\title{
A novel hypoxia-dependent 2-nitroimidazole KIN-84I inhibits tumour-specific angiogenesis by blocking production of angiogenic
} factors

\author{
M Shimamura*, , H Nagasawa ${ }^{2}$, H Ashino ${ }^{3}$, Y Yamamoto', T Hazato', Y Uto ${ }^{2}$, H Hori $^{2}$ and S Inayama ${ }^{4,5}$ \\ 'Medical R\&D Center, The Tokyo Metropolitan Institute of Medical Science, 3-I 8-22 Honkomagome, Bunkyo-ku, Tokyo I I 3-86 I 3, Japan; ${ }^{2}$ Department \\ of Biological Science and Technology, Faculty of Engineering, The University of Tokushima, Minamijosanjimacho Tokushima 770-8506, Japan; \\ ${ }^{3}$ Department of Molecular Biology, The Tokyo Metropolitan Institute of Medical Science, 3-I 8-22 Honkomagome, Bunkyo-ku, Tokyo II 3-86 I 3, Japan; \\ ${ }^{4}$ Pharmaceutical Institute, School of Medicine, Keio University, 35 Sninanomachi, Shinjuku-ku, Tokyo 160-8582, Japan; ${ }^{5}$ Institute of Oriental Medical \\ Sciences, 2-6-3 Ebisunishi, Shibuya-ku, Tokyo 155-0021, Japan
}

\begin{abstract}
Tumour angiogenesis is initiated by angiogenic factors that are produced in large amounts by hypoxic tumour cells. The inhibition of this step may lead to tumour-specific antiangiogenesis because normal tissues are not usually hypoxic. On the other hand, blocking a biological function of endothelial cells is known to result in angiogenic inhibition. To produce a tumour-specific and powerful antiangiogenesis, we determined whether potent angiogenic inhibition could be achieved by inhibiting the production of angiogenic factors by hypoxic tumour cells and simultaneously blocking certain angiogenic steps in endothelial cells under normoxia. We focused on the 2-nitroimidazole moiety, which is easily incorporated into hypoxic cells and exhibits its cytotoxicity as hypoxic cytotoxin. We designed and synthesised 2-nitroimidazole derivatives designated as KIN compounds, and investigated their antiangiogenic activities under normoxia using a chick embryo chorioallantoic membrane. KIN-84 I (2-nitroimidazole I-acetylhydroxamate) showed a potent angiogenic inhibition in a dose-dependent manner. This compound inhibited the proliferation of bovine pulmonary arterial endothelial (BPAE) cells more strongly than that of tumour cells, such as Lewis lung carcinoma (3LL) cells, under normoxia. The inhibition of cell proliferation by KIN-84I under hypoxia increased about five-fold compared to that under normoxia. Moreover, under hypoxia, KIN$84 \mathrm{I}$ significantly decreased the excessive production of vascular endothelial cell growth factors induced by $3 \mathrm{LL}$ cells as determined by tritium-labelled thymidine $\left(\left[{ }^{3} \mathrm{H}\right]\right.$ thymidine) incorporation into BPAE cells and by ELISA. Intraperitoneal administration of KIN-84 I suppressed 3LL-cell-induced in vivo angiogenesis in the mouse dorsal air sac system. These results indicate that the regulation of the production of angiogenic factors by hypoxic tumour cells is a useful target for tumour-specific angiogenesis inhibition, and that KIN-84I, which causes simultaneous direct inhibition of endothelial cell function and production of angiogenic factors by hypoxic tumour cells, is a very potent inhibitor of tumour-specific angiogenesis. Thus, the potential for clinical use of KIN-84I as an antitumour drug is very high. British Journal of Cancer (2003) 88, 307-313. doi:I0.1038/sj.bjc.6600667 www.bjcancer.com
\end{abstract}

(c) 2003 Cancer Research UK

Keywords: angiogenesis; endothelial cells; hypoxia; angiogenic factor; nitroimidazole

Angiogenesis is the formation of new blood vessels, and is essential for tissue development, regeneration and remodelling (Folkman and Shing, 1992). Angiogenesis also plays an important role in many pathological processes, such as growth and metastasis of solid tumour, diabetic retinopathy, rheumatoid arthritis and psoriasis. The inhibition of angiogenesis results in a suppression of these diseases.

The initiation of angiogenesis is associated with some changes in the environment affecting the equilibrium between angiogenic factors and inhibitors. Hypoxia is considered as the leading cause of angiogenesis. In solid tumours, hypoxia exists between the aerobic region near the capillary blood vessels and the anaerobic region where necrotic cells are present. Hypoxia is a common feature of human and animal tumours (Moulder and Rockwell,

*Correspondence: Dr M Shimamura; E-mail: mshima@rinshoken.or.jp Received 19 April 2002; revised 5 September 2002; accepted 18 September 2002
1984; Urtasun et al, 1986). Recently, the expression of vascular endothelial growth factor (VEGF) was shown to increase significantly in human gliomas under hypoxic conditions (Shweiki et al, 1992). In human melanoma cells xenografted to nude mice, the mRNAs coding for VEGFs were significantly elevated under hypoxia, which resulted in tumour angiogenesis (Potgens et al, 1995). Hypoxia thus upregulates the expression of VEGF in tumour cells, which subsequently leads to angiogenesis. Therefore, the downregulation of the production of angiogenic factors by hypoxic tumour cells is a potential therapeutic method of inhibiting tumour-specific angiogenesis. On the other hand, inhibition of certain steps in the angiogenic process in endothelial cells, such as proliferation, migration and tube formation, undoubtedly results in antiangiogenesis. Simultaneously reducing the levels of angiogenic factors in hypoxic tumour cells and blocking the biological function of endothelial cells under normoxia can induce much more potent angiogenic inhibition in solid tumours.

Hypoxic tumour cells represent a significant problem in radiation therapy and chemotherapy since they are resistant to 
$\mathrm{X}$-ray and antitumour drugs. The use of a radiosensitiser with an affinity for hypoxic tumour cells and a probe for the detection and quantitation of hypoxia regions in tumours is important for developing appropriate therapeutic modalities against hypoxic tumour cells. Nitroimidazole derivatives have been studied extensively for use as radiosensitisers (Sheldon et al, 1974; Brown, 1975) and molecular markers of hypoxic regions in solid tumours (Walton and Workman, 1987; Aboagye et al, 1995). 2-Nitroimidazole derivatives, such as misonidazole and etanidazole, have been reported to have potent radiosensitising ability (Sheldon et al, 1974; Brown et al, 1981), and have been clinically studied regarding their application in the radiotherapy of patients with malignant tumours (Chang et al, 1998; Grigsby et al, 1999). The efficiencies of nitroimidazoles as hypoxic radiosensitisers depend on the selective and irreversible binding to the reactive metabolite of the nitro group having one-electron reduction potentials to target molecules in hypoxic tumour cells (Adams et al, 1979). Although nitroimidazole derivatives have been developed as radiosensitisers, they also show preferential toxicity to hypoxic cells as hypoxic cytotoxins (Stratford and Stephens, 1989; Papadopoulou et al, 1996). The cytotoxicity of nitroheterocycles such as misonidazole and etanidazole toward hypoxic cells is a result of abstraction of hydrogen from target molecules by free radicals formed in the reduction of the nitro group. The efficiencies of both radiosensitising activity and cytotoxicity toward hypoxic tumour cells depend on the nitro group of 2nitroimidazoles (Varghese and Whitmore, 1980; Bump et al, 1983). We designed and synthesised 2-nitroimidazole derivatives termed KIN compounds, and showed that KIN-802 and KIN-806 are potent hypoxic cell radiosensitisers (Hori et al, 1989; Nagasawa et al, 1992).

In this study, we achieved potent inhibition of tumour-specific angiogenesis by inhibiting certain angiogenic steps under both normoxia and hypoxia using the novel hypoxic-dependent 2 nitroimidazole KIN-841.

\section{MATERIALS AND METHODS}

\section{Compounds}

All the KIN compounds tested (namely KIN-801, KIN-804, KIN$806, \mathrm{KIN}-808$, KIN-811, KIN-831 and KIN-841), which were 2nitroimidazole derivatives with a moiety of $-\left(\mathrm{CH}_{2}\right)_{n} \mathrm{CONHR}$ in the side chain, were synthesised and their structures were identified based on the physical and spectral data as described previously (Hori et al, 1989; Nagasawa et al, 1992). Misonidazole, etanidazole and 2-nitroimidazole were obtained from Nippon Roche (Tokyo, Japan). The anti-mouse VEGF polyclonal antibody and ELISA kit for the determination of mouse VEGFs were purchased from R\&D Systems Inc. (Minneapolis, MN, USA).

\section{Cells}

Bovine pulmonary arterial endothelial (BPAE) cells were obtained from Dr T Takano (Jintan Terumo, Kanagawa, Japan). Lewis lung carcinoma and cultured Lewis lung carcinoma (3LL) cells were from Dr T Sakurai (Keio University, Tokyo, Japan). 3LL cells were grown in Eagle's medium supplemented with $10 \%$ fetal calf serum (FCS) and BPAE cells were maintained in Dulbecco's MEM containing $10 \%$ FCS.

\section{Chick embryo chorioallantoic membrane assay}

Angiogenic activity was assayed using a chick embryo chorioallantoic membrane (CAM) as described previously (Shimamura et al, 2001). Using a 4-day-old chick embryo (Ohmiya Kakin Laboratories, Ohmiya, Japan) in a shell, $10 \mu \mathrm{l}$ of sample mixed in $1 \%$ methyl cellulose $/ 0.9 \% \mathrm{NaCl}$ was applied to the ring on the surface of the CAM. After $48 \mathrm{~h}$ of exposure at $37^{\circ} \mathrm{C}$, a fat emulsion (Mitsubishi Pharma Corporation, Osaka, Japan) was injected into the CAM to visualise clearly the blood vessels. Each experimental group included six eggs, and experiments were repeated five times. Angiogenic inhibition was indicated by the presence of a 3-mmdiameter avascular zone around the ring (Oikawa and Shimamura, 1996; Yamaji et al, 1999). Inhibition of angiogenesis (\%) means (number of eggs showing at least $3 \mathrm{~mm}$ zone of inhibition)/ (number of eggs used in each experimental group) $\times 100$.

\section{Cell proliferation under normoxic condition}

Cultured BPAE cells and 3LL cells were seeded on 24-multiwell plates at $5 \times 10^{4}$ cells per well in a medium containing $10 \%$ FCS. After $24 \mathrm{~h}$ of incubation, the medium was discarded and various concentrations of KIN-841 in fresh medium containing 3\% FCS were added. On day 3 , the cells were trypsinised and counted using a Coulter counter. Each experimental group included five wells, and experiments were repeated three times.

\section{Cell proliferation under hypoxic condition}

3LL cells were seeded on Petri dishes at $5 \times 10^{4}$ cells ml $^{-1}$ in a medium containing $10 \%$ FCS. After $24 \mathrm{~h}$ of incubation, the medium was discarded and the cells were washed with PBS. Fresh medium containing 5\% FCS and various concentrations of KIN841 were added into the Petri dishes, which were incubated for $48 \mathrm{~h}$ under hypoxic conditions. For incubation under hypoxia, the cells in the Petri dishes were arranged in acrylic Lucite chambers to which a gas mixture $\left(95 \% \mathrm{~N}_{2}-5 \% \mathrm{CO}_{2}\right)$ was infused at a flow rate of $1 \mathrm{lmin}^{-1}$ (Iizuka et al, 1994). Control endothelial cells were maintained under normoxia. The cells in the Petri dishes were trypsinised and counted using a Coulter counter. Each experimental group included five wells, and experiments were repeated three times.

\section{Angiogenic factor production}

3LL cells were cultured in the medium containing 10\% FCS. At confluence, the medium was changed to a serum-free one with or without various concentrations of KIN-841. After incubation for $24 \mathrm{~h}$ under normoxia or hypoxia, the conditioned medium (CM) was collected for the assay of $\left[{ }^{3} \mathrm{H}\right]$ thymidine incorporation in BPAE cells and for ELISA. For $\left[{ }^{3} \mathrm{H}\right]$ thymidine incorporation, $3 \times 10^{4}$ BPAE cells were seeded on 96-well plates. After $24 \mathrm{~h}$ the medium was discarded, and serum-free medium and the five-fold diluted CM obtained from 3LL cells treated with or without KIN-841 were added to the wells. On the other hand, for the assay of the direct effect of KIN-841 on BPAE cells, an appropriately diluted $\mathrm{KIN}-841$-free $\mathrm{CM}$ from normoxic or hypoxic 3LL cells was mixed with various concentrations of KIN-841 and added to the BPAE cell-seeded wells. For the assay with anti-mouse VEGF-neutralizing antibody, a diluted CM from hypoxic or normoxic 3LL cells was mixed with antimouse VEGF antibody $(1: 1000)$ for the 24 -h incubation at $4^{\circ} \mathrm{C}$, and then added to the BPAE cell-seeded wells for $\left[{ }^{3} \mathrm{H}\right]$ thymidine incorporation assay. The treated BPAE cells were incubated for $8 \mathrm{~h}$, and then $37 \mathrm{kBq}$ per well of thymidine[methyl- ${ }^{3} \mathrm{H}$ ] (NEN, Wilmington, DE, USA) was added. After $16 \mathrm{~h}$ of incubation, the medium was discarded and the cells were washed with PBS and lysed in $4 \% \mathrm{Na}_{2} \mathrm{CO}_{3} / 2 \mathrm{~N} \mathrm{NaOH}$. The radioactivity in $20 \mu \mathrm{l}$ of the cell lysate was determined using a scintillation counter. The presence of VEGF in the CM from 3LL cells was evaluated using ELISA. Each experimental group included three wells, and experiments were repeated three times. 


\section{Dorsal air sac assay}

Millipore chambers covered with filters $(0.45-\mathrm{mm}$ pore size) were filled with either saline or $4 \times 10^{6} 3 \mathrm{LL}$ cells, and were implanted s.c. in dorsal air sacs created surgically by injection of an appropriate volume of air to 7-week-old female ICR mice (Charles River Co. Ltd, Yokohama, Japan). The mice were administered with KIN-841 $\left(200 \mathrm{mg} \mathrm{kg}^{-1} \mathrm{day}^{-1}\right)$ or saline intraperitoneally for 4 days between days 1 and 6 . On day 7, mice were killed under diethyl ether and the skin was carefully removed. Each experimental group included six mice, and experiments were repeated twice. Angiogenesis was graded using four angiogenesis indices of 1, 2, 3 and 4 according to the modified method previously described (Lee et al, 1987). Grade 1 means no angiogenesis, while grade 4 indicates the most pronounced angiogenesis.

All surgical procedures were performed under pentobarbital anesthesia (Dainabot, Osaka, Japan). The animal ethics in all animal experiments met the standards required by the UKCCR Guidelines for the Welfare of Animals on Experimental Neoplasia (second edition), as stated in the 'Instructions to Authors' forms.

\section{Statistical analysis}

Results are presented as mean \pm s.e.m. Statistical comparisons were performed using the paired Student's $t$-test. DAS analysis was performed according to the Mann-Whitney $U$-test. A probability value of $P<0.05$ was considered significant.

\section{RESULTS}

\section{Effect of KIN-841 on angiogenesis in CAM}

The antiangiogenic activities of ten 2-nitroimidazole derivatives (including seven KIN compounds (KIN-801, KIN-804, KIN-806, KIN-808, KIN-811, KIN-831 and KIN-841), two known 2nitroimidazole derivatives (misonidazole and etanidazole) and 2nitroimidazole) were determined in the presence of $200 \mu \mathrm{g} \mathrm{CAM}^{-1}$ using CAM assay under normoxic condition. KIN-808 and KIN841 were found to inhibit angiogenesis $(52.3 \pm 2.9$ and $75.3 \pm 1.7 \%$, respectively). On the other hand, the inhibitory activities of misonidazole and etanidazole were low $(17.8 \pm 3.8$ and $38.7 \pm 1.9 \%$, respectively). Among the compounds tested, the most potent inhibitor was $\mathrm{KIN}-841$ with a $\mathrm{CH}_{2}\left(\mathrm{CH}_{2}\right)_{2} \mathrm{CONHOH}$ moiety at the 1position of 2-nitroimidazole in the molecule (Figures 1 and 2A,B). $\mathrm{KIN}-841$ suppressed the in vivo angiogenesis dose-dependently with an $\mathrm{ED}_{50}$ of $50 \mu \mathrm{g} \mathrm{CAM}^{-1}$ (Figure $2 \mathrm{C}$ ).

\section{Effect of KIN-841 on proliferation of endothelial cells and tumour cells under normoxia}

BPAE cells and $3 \mathrm{LL}$ cells were incubated with various concentrations of KIN-841 in the proliferation assay (Figure 3). KIN-841

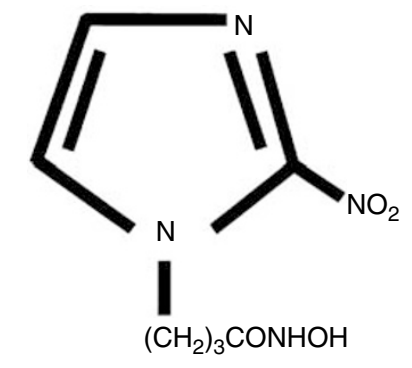

Figure I Structure of KIN-84I.
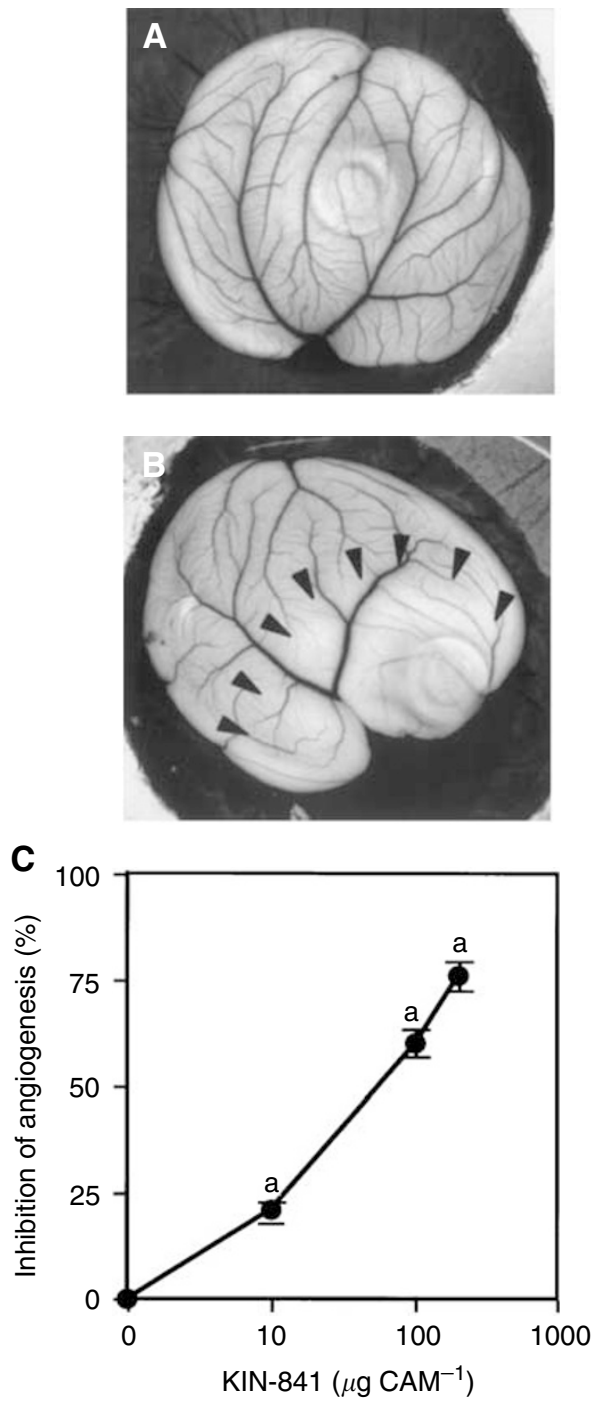

Figure 2 Inhibitory effect of $\mathrm{KIN}-84$ I on in vivo angiogenesis in CAM. No (A) or $100 \mu \mathrm{g} \mathrm{ml}^{-1}$ (B) KIN-84I was added to the CAM surfaces of 4-dayold fertilized eggs, and then the eggs were incubated for $48 \mathrm{~h}$ as described in Materials and Methods. KIN-84I produced an avascular zone (surrounded by arrows), indicating angiogenic inhibition. (C) Dosedependent inhibition of in vivo angiogenesis in CAM by $\mathrm{KIN}-84 \mathrm{I}$. ${ }^{a} P<0.0$ I vs controls.

showed a direct inhibitory effect on the proliferation of BPAE cells at $10^{-4} \mathrm{M}(P<0.05)$. On the other hand, the proliferation of $3 \mathrm{LL}$ cells was not inhibited by $10^{-4} \mathrm{M} \mathrm{KIN-841}$. KIN-841 showed a more potent inhibition of the proliferation against the endothelial cells than of tumour cells $(P<0.05)$.

\section{Effect of KIN-841 on proliferation of tumour cells under hypoxia}

Previously, all the compounds tested other than 2-nitroimidazole in CAM assay under normoxia were reported to exhibit similar high levels of radiosensitising activity against hypoxic tumour cells (Nagasawa et al, 1992). The radiosensitising activity was shown to correlate with specific cytotoxicity in hypoxic tumour cells. Therefore, subsequent experiments under hypoxic condition were carried out with the most potent angiogenic inhibitor under normoxia, KIN-841. 3LL cells were cultured with or without KIN- 


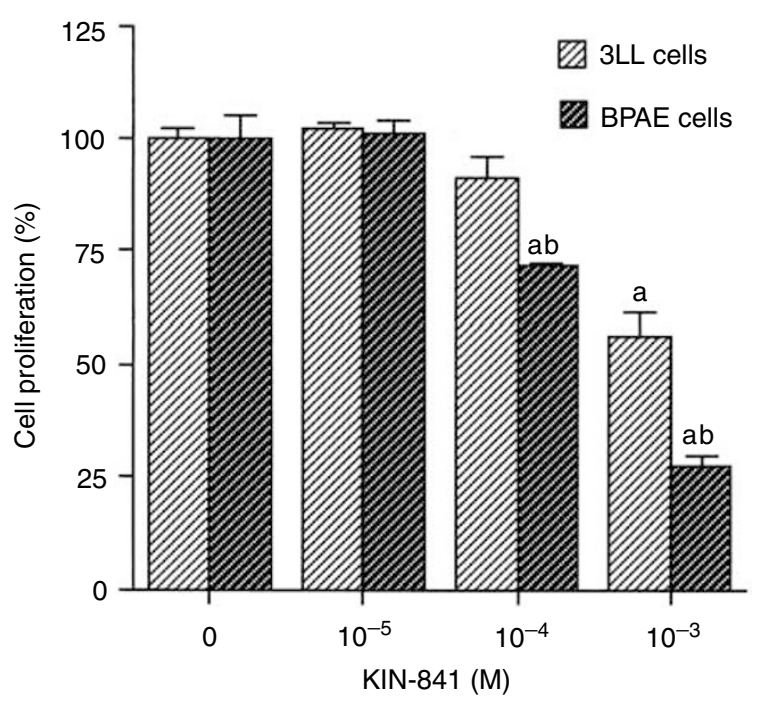

Figure 3 Inhibitory effect of $\mathrm{KIN}-84 \mathrm{I}$ on proliferation of BPAE cells and $3 \mathrm{LL}$ cells under normoxia. Cells were treated for $48 \mathrm{~h}$ with $\mathrm{KIN}-84 \mathrm{I}$ at the various concentrations indicated. ${ }^{\mathrm{a}} P<0.05$ vs controls; ${ }^{\mathrm{b}} \mathrm{P}<0.05$ vs normoxia.

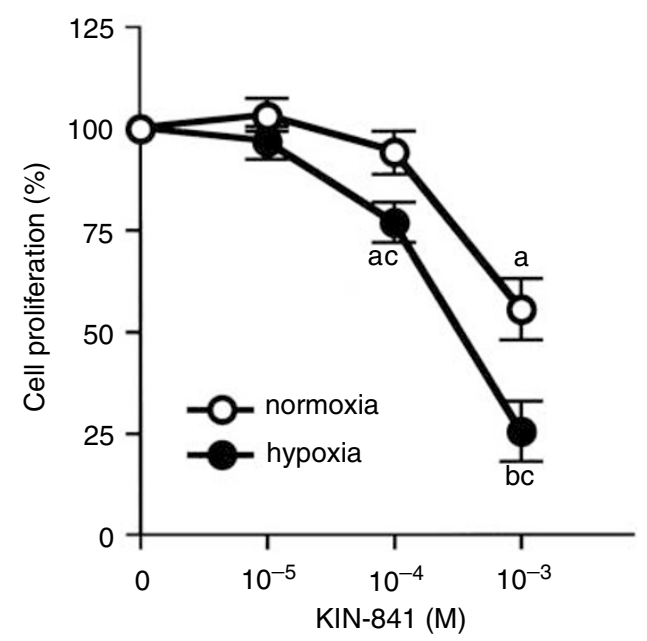

Figure 4 Inhibitory effect of KIN-84I on proliferation of $3 \mathrm{LL}$ cells under hypoxia. Cells were treated for $48 \mathrm{~h}$ with $\mathrm{KIN}-84 \mathrm{I}$ at the various concentrations indicated under normoxia or hypoxia. ${ }^{\text {a }}<<0.05$ vs controls; ${ }^{b} P<0.01$ vs controls; ${ }^{c} P<0.05$ vs normoxia.

841 in culture chambers under hypoxia or normoxia for $48 \mathrm{~h}$ (Figure 4). Under the hypoxic conditions, the cell growth was slow and KIN-841 inhibited the proliferation of 3LL cells at $10^{-4}-10^{-3} \mathrm{M}(P<0.01)$. On the other hand, this inhibitory activity was weak when the cells were cultured under normoxic conditions $(P<0.05 v s$ hypoxia). The inhibition of $\mathrm{KIN}-841$ on $3 \mathrm{LL}$ cell proliferation was about five times more potent under hypoxia than under normoxia.

\section{Effect of KIN-841 on production of angiogenic factor by hypoxic tumour cells}

It is well known that hypoxic tumour cells produce significant amounts of many kinds of factors that initiate angiogenesis. To determine whether KIN-841 suppresses the production of angiogenic factors by $3 \mathrm{LL}$ cells under hypoxia, the serum-free CM was obtained from $3 \mathrm{LL}$ cells that were treated with various concentra- tions of KIN-841 under normoxia or hypoxia. The levels of the angiogenic factors in the $\mathrm{CM}$ were measured by $\left[{ }^{3} \mathrm{H}\right]$ thymidine incorporation into BPAE cells (Figures $5 \mathrm{~A}$ and $\mathrm{B}$ ) and by ELISA (Figure 5C). The CM from 3LL cells cultured under hypoxia significantly stimulated thymidine uptake into BPAE cells compared with that obtained from the cells cultured under normoxia $(P>0.05$, Figure $5 \mathrm{~A})$. This activity in $\mathrm{CM}$ of hypoxic tumour cells was 1.8 times higher than that in normoxic cells. The stimulating activity was decreased when the tumour cells were incubated with KIN-841 under hypoxia $(P>0.01$, Figure 5A). In contrast, the direct addition of KIN-841 did not block the thymidine uptake induced by the CM from 3LL cells (Figure 5B). However, the antimouse VEGF antibody potently blocked the stimulating activity of the $\mathrm{CM}$ from hypoxic tumour cells, suggesting that the angiogenic factors in the CM are VEGFs (Figure 5B). Figure 5C shows the levels of VEGF in the CM of 3LL cells treated with various concentrations of KIN-841 under the same conditions as in Figure 5A. In 3LL cells, VEGF production was significantly induced by hypoxia $(P<0.01)$, and KIN-841 at $10^{-5}-10^{-4} \mathrm{M}$ substantially inhibited VEGF production $(P<0.05)$.

\section{Effect of KIN-841 on tumour-induced angiogenesis}

To determine whether KIN-841 might have therapeutic value in vivo in the treatment of tumour-induced angiogenesis, the effect of KIN-841 on 3LL-cell-induced angiogenesis was investigated using the mouse dorsal air sac method (Figure 6). In mice implanted with a Millipore chamber containing saline, angiogenesis hardly occurred (group A, Figure 6A). On the other hand, in the mice of group $\mathrm{B}$, implanted with a chamber containing $3 \mathrm{LL}$ cells and then treated with saline, potent angiogenesis was induced (Figure 6B). When the mice were intraperitoneally administered with $200 \mathrm{mg} \mathrm{kg}^{-1} \mathrm{day}^{-1}$ of KIN-841 (group C, Figure 6C), the angiogenesis was significantly suppressed. The angiogenesis indexes of group B (3LL cells alone) and group C (3LL cells and KIN-841) were $3.2 \pm 0.44$ and $1.75 \pm 0.20$, respectively (Figure 6D). KIN-841 significantly inhibited in vivo angiogenesis induced by $3 \mathrm{LL}$ cells in the dorsal air sac assay $(P<0.05)$.

\section{DISCUSSION}

Tumour angiogenesis is a complex multistep process involving the following: (1) production of angiogenic factors by tumour cells, especially hypoxic tumour cells; (2) upregulation of the biological functions of vascular endothelial cells by angiogenic factors; (3) degradation of the basement membrane of endothelial cells by enzymes; (4) migration of endothelial cells; (5) proliferation of endothelial cells; and (6) tube formation of endothelial cells. Interruptions in certain steps of this series of biochemical events may prevent angiogenesis. In particular, the inhibition of the early steps of the process may promote antiangiogenesis. The prevention of the first step of angiogenesis that involves the production of angiogenic factors by hypoxic tumour cells is potently effective in promoting tumour-specific antiangiogenesis.

There are many factors implicated in angiogenesis. The production of several angiogenic factors, including VEGF, bFGF and PDGF (Minchenko et al, 1994; Gleadle et al, 1995; Kuwabara et al, 1995), is upregulated by hypoxia. In solid tumours, a more rapid increase in the number of oxygen-consuming tumour cells than can be sustained by the oxygen supply to the cells from the microvasculature occurs, resulting in tissue hypoxia. Continuous hypoxia results in the expression of the genes coding for angiogenic factors, which are produced in secretory forms. Angiogenic factors act on their receptors on endothelial cells in an autocrine and paracrine manner, thereby causing the activation of endothelial cells, which leads to angiogenesis and subsequent progressive tumour growth and metastasis. Therefore, the preven- 

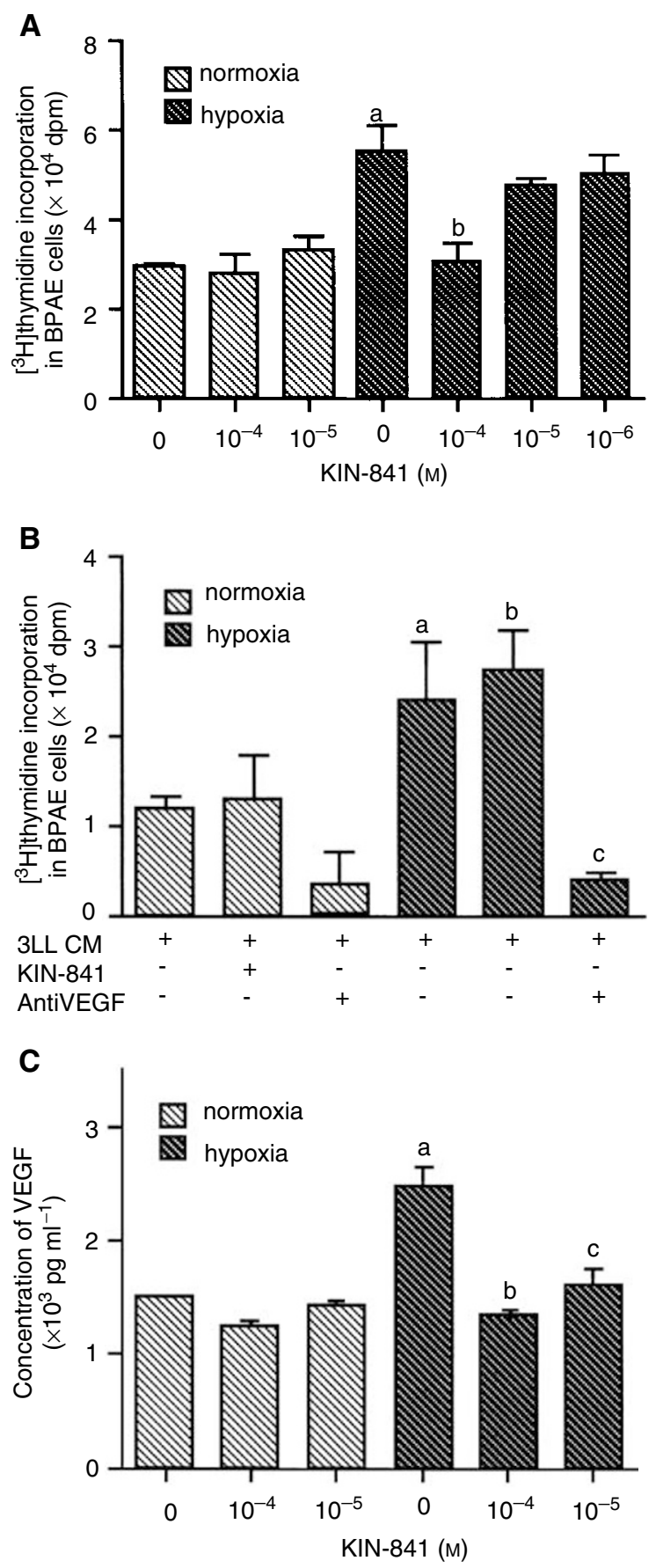

Figure 5 Inhibitory effect of $\mathrm{KIN}-84 \mathrm{I}$ on the production of angiogenic factor in $3 \mathrm{LL}$ cells under hypoxia. (A) Effect of $3 \mathrm{LL}$ cell-CM treated with $\mathrm{KIN}-84 \mathrm{I}$ at the various concentrations indicated under normoxia or hypoxia on $\left[{ }^{3} \mathrm{H}\right]$ thymidine incorporation in BPAE cells. ${ }^{a} P<0.01$ vs normoxia controls; ${ }^{P} P<0.01$ vs hypoxia controls. (B) Effects of $\mathrm{KIN}-84$ I and anti-VEGF antibody on stimulation of $\left.{ }^{3} \mathrm{H}\right]$ thymidine incorporation in BPAE cells by $3 L L$ cell-CM incubated under normoxia or hypoxia. ${ }^{a} P<0.05$ vs normoxia controls; ${ }^{b} P<0.05$ vs normoxia controls; ${ }^{c} P<0.0$ I vs hypoxia controls. (C) VEGF concentration in $3 \mathrm{LL}$ cell-CM treated with $\mathrm{KIN}-84$ I at the various concentrations indicated under normoxia or hypoxia. ${ }^{\mathrm{a}} \mathrm{P}<0.05$ vs normoxia controls; ${ }^{b} P<0.05$ vs hypoxia controls; ${ }^{c} P<0.0$ l vs hypoxia controls.

tion of the production of angiogenic factors in hypoxic tumour cells may result in the potent inhibition of angiogenesis, tumour growth and metastasis.
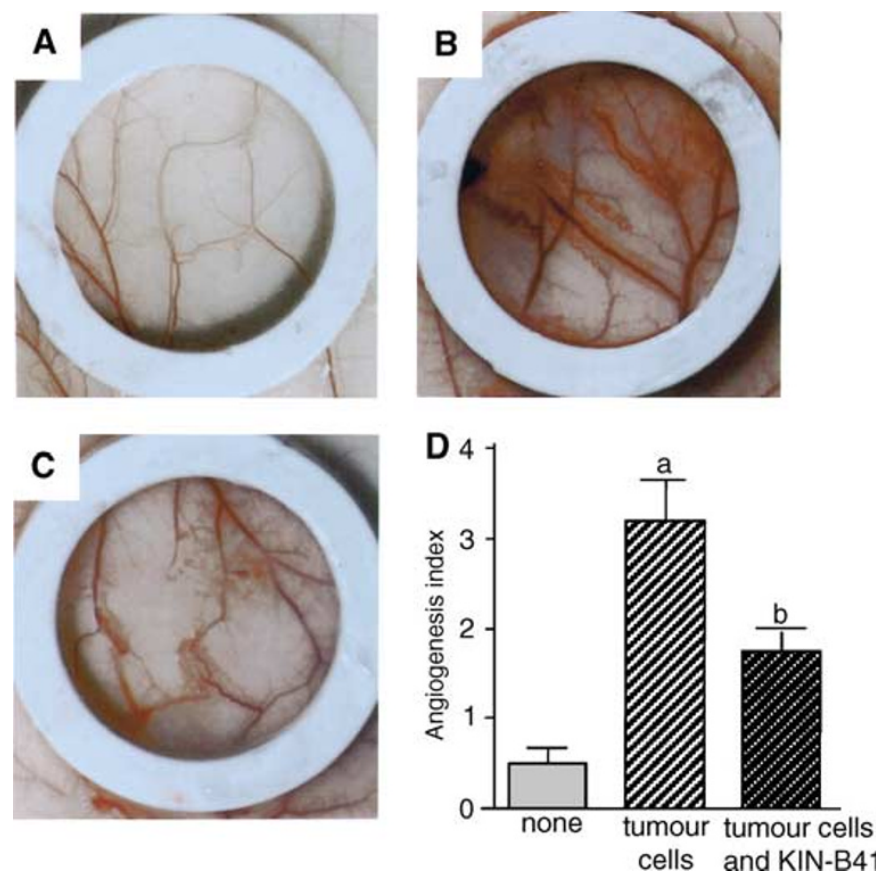

Figure 6 Inhibition of 3LL-cell-induced angiogenesis by KIN-84I as determined using the mouse dorsal air sac method. Dorsal skin of the mice 7 days after implantation of a chamber filled with PBS alone $(\mathbf{A})$ or $3 \mathrm{LL}$ cells (B and C). The implanted mice were treated with $200 \mathrm{mg} \mathrm{kg}^{-1} \mathrm{day}^{-1}$ of KIN-84 I for 4 days between days I and 6, intraperitoneally (C). In (D), the grade of angiogenesis induced by $3 \mathrm{LL}$ cells is shown using the indexes described in Materials and Methods. ${ }^{a} P<0.01$ tumour-free controls; ${ }^{\mathrm{b}} \mathrm{P}<0.05$ vs tumour controls.

In this study, we attempted to (1) inhibit the production of angiogenic factors in hypoxic tumour cells using 2-nitroimidazole derivatives, which covalently bind to hypoxic tumour cells and are cytotoxic against hypoxic tumour cells, and (2) simultaneously disrupt the endothelial cell function using the same agent, to achieve potent inhibition of tumour-specific angiogenesis. We found the hypoxia-dependent 2-nitroimidazole KIN-841, with a hydroxamate moiety in the side chain, to be the most potent angiogenic inhibitor by an in vivo assay using the CAM under normoxia (Figures 1 and 2).

In order to determine the antiangiogenic mechanism of KIN841, its effect on the proliferation of endothelial cells was examined. KIN-841 inhibited the proliferation of vascular endothelial cells under normoxia (Figure 3). Its inhibitory effect on endothelial cells was more potent than that on tumour cells. These results suggest that $\mathrm{KIN}-841$ inhibits angiogenesis by disrupting vascular endothelial cell growth. Under hypoxic conditions, KIN841 inhibited the proliferation of tumour cells more potently than under normoxia (Figure 4). The CM from 3LL cells under hypoxia could stimulate $\left[{ }^{3} \mathrm{H}\right]$ thymidine incorporation into vascular endothelial cells. This stimulating activity in $\mathrm{CM}$ was estimated to be because of the presence of VEGFs (Figure 5B, C). In contrast, the $\mathrm{CM}$ of KIN-841-treated hypoxic tumour cells decreased the stimulating activity and VEGF level (Figure 5A, C). KIN-841 did not directly inhibit the stimulating activity (Figure 5B). These results indicated that $\mathrm{KIN}-841$ can suppress the production of angiogenic factors, VEGFs, derived from hypoxic tumour cells and may inhibit tumour-specific angiogenesis.

There is no question regarding the importance of VEGFs in angiogenesis and expansion of solid tumours, because VEGF particularly affects vascular endothelial cells and, consequently, stimulates all steps of angiogenesis. However, several reports 
revealed that angiogenic factors other than VEGF play important roles in angiogenesis (Hartmann et al, 1999; Koga et al, 2001; Shimo et al, 2001). In melanoma cell lines, a strong correlation between VEGF expression and tumorigenesis was not observed, although VEGF production was induced under the hypoxic condition (Hartmann et al, 1999). Angiogenin production was reported to be upregulated in melanoma cell lines but not in normal melanocytes under hypoxic condition. The level of induction of angiogenin correlated with the metastatic potential of the cell lines. Furthermore, a strong expression of angiogenin was observed in melanomas and metastases from patients, but was not observed in benign nevi. These indicated that angiogenin is the most potent angiogenic factor in melanomas. Various approaches to inhibiting angiogenic factor signalling pathways have been adopted using specific antibodies against various angiogenic factors. A monoclonal antibody against VEGF inhibited angiogenesis and prevented tumour growth in solid tumours (Borgstrom et al, 1996; Brekken and Thorpe, 2001). However, a specific antibody against one angiogenic factor cannot completely inhibit angiogenesis, which depends on two or more factors or a different type of angiogenic factor. This problem may be overcome if hypoxia-induced angiogenic factor-producing cells can be attacked and the production of angiogenic factors by hypoxic cells can be inhibited. KIN-841 may be able to inhibit the production of all types of hypoxia-induced angiogenic factors in tumour cells.

We further determined the effect of KIN-841 on tumour-induced angiogenesis using the mouse dorsal air sac method. KIN-841 exhibited inhibitory activity on the angiogenic response triggered

\section{REFERENCES}

Aboagye EO, Lewis AD, Johnson A, Workman P, Tracy M, Huxham IM (1995) The novel fluorinated 2-nitroimidazole hypoxia probe SR-4554 reductive metabolism and semiquantitative localisation in human ovarian cancer multicellular spheroids as measured by electron energy loss spectroscopic analysis. Br J Cancer 72: 312-318

Adam MF, Gabalski EC, Bloch DA, Oehlert JW, Brown JM, Elsaid AA, Pinto HA, Terris DJ (1999) Tissue oxygen distribution in head and neck cancer patients. Head Neck 21: 146-153

Adams GE, Clarke ED, Flockhart IR, Jacobs RS, Sehmi DS, Stratford IJ, Wardman P, Watts ME, Parrick J, Wallace RG, Smithen CE (1979) Structure-activity relationships in the development of hypoxic cell radiosensitizers. I. Sensitization efficiency. Int J Radiat Biol Relat Stud Phys Chem Med 35: 133-150

Borgstrom P, Hillan KJ, Sriramarao P, Ferrara N (1996) Complete inhibition of angiogenesis and growth of microtumours by anti-vascular endothelial growth factor neutralizing antibody: novel concepts of angiostatic therapy from intravital videomicroscopy. Cancer Res 56: 4032-4039

Brekken RA, Thorpe PE (2001) Vascular endothelial growth factor and vascular targeting of solid tumours. Anticancer Res 21: 4221-4229

Brown JM (1975) Selective radiosensitization of the hypoxic cells of mouse tumours with the nitroimidazoles metronidazole and Ro 7-0582. Radiat Res 64: 633-647

Brown JM, Yu NY, Brown DM, Lee WW (1981) SR-2508: a 2-nitroimidazole amide which should be superior to misonidazole as a radiosensitizer for clinical use. Int J Radiat Oncol Biol Phys 7: 695-703.

Bump EA, Taylor YC, Brown JM (1983) Role of glutathione in the hypoxic cell cytotoxicity of misonidazole. Cancer Res 43: 997-1002

Chang EL, Loeffler JS, Riese NE, Wen PY, Alexander Er, Black PM, Coleman CN (1998) Survival results from a phase I study of etanidazole (SR2508) and radiotherapy in patients with malignant glioma. Int J Radiat Oncol Biol Phys 40: 65-70

Folkman J, Shing Y (1992) Angiogenesis. J Biol Chem 267: 10931-10934

Gleadle JM Ebert BL Firth JD, Ratcliffe PJ (1995) Regulation of angiogenic growth factor expression by hypoxia, transition metals, and chelating agents. Am J Physiol 268: C1362-C1368

Grigsby PW, Winter K, Wasserman TH, Marcial V, Rotman M, Cooper J, Keys H, Asbell SO, Phillips TL (1999) Irradiation with or without by mouse malignant 3LL cells (Figure 6). This result suggested that KIN-841 inhibits tumour growth and metastasis in vivo by disrupting angiogenesis. Recently, the oxygen tensions in a neck node of a squamous cell carcinoma and adjacent normal tissue were measured (Adam et al, 1999). Normal tissue showed a typical Gaussian distribution of oxygen tensions with a median value between 40 and $60 \mathrm{mmHg}$. On the other hand, tumours showed a distribution of much lower oxygen tension with a median value of less than $10 \mathrm{mmHg}$. Since the oxygen tension in normal tissue is slightly low, KIN-841 may express more potent in vivo antiangiogenesis because of its high affinity to hypoxic tumour cells and slightly hypoxic endothelial cells.

In conclusion, potent inhibition of tumour-specific angiogenesis can be induced by simultaneously preventing the production of angiogenic factors by hypoxic tumour cells and vascular endothelial cell function involved in cell proliferation under normoxia in the presence of a novel hypoxia-dependent 2-nitroimidazole derivative, KIN-841. Furthermore, the hypoxia-dependent KIN841 may be able to target effectively tumour-associated vasculatures and exhibit potent antiangiogenic activity in solid tumours and prevent tumour metastasis.

\section{ACKNOWLEDGEMENTS}

We thank Dr T Iwaguchi for insightful and stimulating advice. This work was supported by a research grant from the Ministry of Education, Culture, Sports, Science and Technology of Japan. misonidazole for patients with stages IIIB and IVA carcinoma of the cervix: final results of RTOG 80-05. Radiation Therapy Oncology Group. Int J Radiat Oncol Biol Phys 44: 513-517

Hartmann A, Kunz M, Kostlin S, Gillitzer R, Toksoy A, Brocker EB, Klein CE (1999) Hypoxia-induced up-regulation of angiogenin in human malignant melanoma. Cancer Res 59: 1578-1583

Hori H, Murayama C, Mori T, Shibamoto Y, Abe M, Onoyama Y, Inayama S (1989) KIH-802: 2-nitroimidazole-1-acetohydroxamate as a hypoxic cell radiosensitizer. Int J Radiat Oncol Biol Phys 16: 1029-1032

Iizuka M, Yamauchi M, Ando K, Hori N, Furusawa Y, Itsukaichi H, Fukutsu K, Moriya H (1994) Quantitative RT-PCR assay detecting the transcriptional induction of vascular endothelial growth factor under hypoxia. Biochem Biophys Res Commun 205: 1474-1480

Koga K, Todaka T, Morioka M, Hamada J, Kai Y, Yano S, Okamura A, Takakura N, Suda T, Ushio Y (2001) Expression of angiopoietin-2 in human glioma cells and its role for angiogenesis. Cancer Res 61: 62486254

Kuwabara K, Ogawa S, Matsumoto M, Koga S, Clauss M, Pinsky DJ, Lyn P, Leavy J, Witte L, Joseph SJ, Firie M, Torcia G, Cozzolino F, Kamada T, Stern D (1995) Hypoxia-mediated induction of acidic/basic fibroblast growth factor and platelet-derived growth factor in mononuclear phagocytes stimulates growth of hypoxic endothelial cells. Proc Natl Acad Sci USA 92: 4606-4610

Lee K, Erturk E, Mayer R, Cockett AT (1987) Efficacy of antitumour chemotherapy in $\mathrm{C} 3 \mathrm{H}$ mice enhanced by the antiangiogenesis steroid, cortisone acetate. Cancer Res 47: 5021-5024

Minchenko A, Salceda S, Bauer T, Caro J (1994) Hypoxia regulatory elements of the human vascular endothelial growth factor gene. Cell Mol Biol Res 40: 35-39

Moulder JE, Rockwell S (1984) Hypoxic fractions of solid tumours: experimental techniques, methods of analysis, and a survey of existing data. Int J Radiat Oncol Biol Phys 10: 695-712

Nagasawa H, Bando M, Hori H, Satoh T, Tada T, Onoyama Y, Inayama S (1992) Radiosensitizing, toxicological, and pharmacokinetic properties of hydroxamate analogues of nitroimidazoles as bifunctional radiosensitizers/chemical modifiers. Int J Radiat Oncol Biol Phys 22: 561-564

Oikawa T, Shimamura M (1996) Potent inhibition of angiogenesis by wortmannin, a fungal metabolite. Eur J Pharmacol 318: 93-96 
Papadopoulou MV, Ji M, Rao, MK, Bloomer WD (1996) 9-[3-(2-Nitro-1imidazolyl)propylamino]-cyclopenteno[b]quinoline hydrochloride (NLCPQ-1). A novel DNA-affinic bioreductive agent as cytotoxin and radiosensitizer. Oncol Res 8: 425-434

Potgens AJ, Lubsen NH, van Altena MC, Schoenmakers JG, Ruiter DJ, de Waal RM (1995) Vascular permeability factor expression influences tumour angiogenesis in human melanoma lines xenografted to nude mice. Am J Pathol 146: 197-209

Sheldon PW, Foster JL, Fowler JF (1974) Radiosensitization of C3H mouse mammary tumours by a 2 -nitroimidazole drug. $\mathrm{Br} J$ Cancer 30: $560-565$

Shimamura M, Hazato T, Ashino H, Yamamoto Y, Iwasaki E, Tobe H, Yamamoto K, Yamamoto S (2001) Inhibition of angiogenesis by humulone, a bitter acid from beer hop. Biochem Biophys Res Commun 289: $220-224$

Shimo T, Kubota S, Kondo S, Nakanishi T, Sasaki A, Mese H, Matsumura T, Takigawa M (2001) Connective tissue growth factor as a major angiogenic agent that is induced by hypoxia in a human breast cancer cell line. Cancer Lett 174: $57-64$
Shweiki D, Itin A, Soffer D, Keshet E (1992) Vascular endothelial growth factor induced by hypoxia may mediate hypoxia-initiated angiogenesis. Nature 359: 843-845

Stratford IJ, Stephens MA (1989) The differential hypoxic cytotoxicity of bioreductive agents determined in vitro by the MTT assay. Int J Radiat Oncol Biol Phys 16: 973-976

Urtasun RC, Koch CJ, Franko AJ, Raleigh JA, Chapman JD (1986) A novel technique for measuring human tissue $\mathrm{pO}_{2}$ at the cellular level. $\mathrm{Br} \mathrm{J}$ Cancer 54: 453-457

Varghese AJ, Whitmore GF (1980) Binding to cellular macromolecules as a possible mechanism for the cytotoxicity of misonidazole. Cancer Res 40: 2165-2169

Walton MI, Workman P (1987) Nitroimidazole bioreductive metabolism. Quantitation and characterisation of mouse tissue benznidazole nitroreductases in vivo and in vitro. Biochem Pharmacol 36: 887-896

Yamaji T, Tsuboi H, Murata N, Uchida M, Kohno T, Sugino E, Hibino S, Shimamura M, Oikawa T (1999) Anti-angiogenic activity of a novel synthetic agent, 9alpha-fluoromedroxyprogesterone acetate. Cancer Lett 145: $107-114$ 